\title{
SOBRE AS RELAÇÕES ENTRE O SEXUAL E O MAL-ESTAR NA CIVILIZAÇÃO: UMA DISCUSSÃO ACERCA DAS PERSPECTIVAS FREUDIANAS
}

\author{
Clara Virginia de Q. Pinheiro* \\ Celina Peixoto Lima** \\ Débora Passos de Oliveira***
}

\section{RESUMO}

O objetivo do presente artigo é examinar as formulaçôes freudianas acerca das relações entre o sujeito às voltas com encontrar possibilidades de satisfação libidinal e o avanço da civilização. Consideramos que podemos estabelecer diferenças entre duas concepçōes freudianas: 1) uma oposição entre sexualidade e coletividade; 2) a civilização como vínculo libidinal. A primeira refere-se ao texto "Moral sexual civilizada e doença nervosa moderna" (1908) e a segunda, ao texto de 1930, "Mal-estar na civilização". A propósito da noção de civilização, estabelecemos uma articulação entre Freud e Norbert Elias, na medida em que partimos da idéia de que o conceito de civilização em Freud remete à experiência propriamente moderna de formação de laço social. Trata-se, com efeito, de uma forma de sociabilidade baseada na auto-regulação.

Palavras-chave: sexualidade, civilização, auto-regulação, Freud, Norbert Elias

\section{Abstract}

ON THE RELATIONSHIP BETWEEN SEXUALITY AND THE DISCONTENT IN CIVILIZATION: A DEBATE REGARDING ON FREUDIAN PERSPECTIVES

This article's aim is to analyze the Freudian formulations regarding the relationship between the subject, occupied with finding possibilities of libidinous satisfaction, and the advance of civilization. We consider that a difference can be established between two Freudian conceptions

* Professora Doutora do Programa de Mestrado em Psicologia - Universidade de Fortaleza.

** Professora Doutora do Programa de Mestrado em Psicologia - Universidade de Fortaleza.

*** Graduanda em Psicologia - bolsista do PIBIC/CNPq. 
1) an opposition between sexuality and collectivity; 2) civilization as a libidinous bond. The first one is found in the text "Civilized sexual morality and modern nervousness" (1908), and the second in the text of 1930, "Civilization and its discontents". Regarding the conception of civilization, we relate ideas of Freud and Norbert Elias, since we consider that the concept of civilization in Freud refers to the modern experience of social bond. Therefore, it is a form of sociability based on self-regulation.

Keywords: sexuality, civilization, self-regulation, Freud, Norbert Elias

\section{INTRODUÇÃO}

O objetivo do presente trabalho é examinar as formulações freudianas acerca das relações entre o sujeito, voltado para as possibilidades de satisfaçóes pulsionais, e a civilização, cuja tendência é a ampliação dos vínculos interpessoais. Trata-se da questão de saber em que medida Freud estabelece uma oposição entre os interesses individuais e o interesse da coletividade. Mostraremos que, mesmo na obra de Freud, há distinções no que se refere ao funcionamento e à correlação entre essas duas dimensões da experiência subjetiva. Para atender a tal questão, nos deteremos em dois textos-chaves de Freud, a saber: "Moral sexual 'civilizada' e doença nervosa moderna” (1908/1996) e o "Mal-estar na civilização" (1930/1996). Veremos que, no primeiro texto, Freud considera que a relação mantida pelo sujeito com a civilização aproxima-se de uma sujeição, e nele encontramos uma dicotomização entre subjetividade e civilização. Dessa forma, as leis que constituem o código de conduta são exteriores e impostas ao sujeito. Já no segundo texto, civilização e sujeito não estão separados, constituem-se mutuamente, e, assim, as interdiçôes passam a ser vistas como formadoras da subjetividade.

Para esta discussão acerca dos processos psíquicos envolvidos na formação da civilização, vamos lançar mão do livro de Nobert Elias (1993), Processo civilizador, para que assim possamos aplicar um conceito temporal e histórico de civilização, já que esse autor delineia o momento e as causas da formação de tal processo. Com isso, temos uma visão que dá primazia à formação da subjetividade, a de Freud, somada a outra que prioriza a sociedade moderna, em Elias. A utilização da obra de Elias mostra-se pertinente aos nossos fins, pois, ao longo do trabalho, empregaremos o conceito de auto-regulação como sendo o mecanismo por excelência que está por trás da sociabilidade moderna.

Tanto Freud (1930/1996) como Elias (1993) consideram que a civilização implica um autogerenciamento que permite ao indivíduo o convívio com os outros. Estariam, porém, esses dois autores referindo-se ao mesmo fenômeno ao se 
reportarem à civilização? Freud conceitua os dispositivos reguladores das relações humanas como o que nos diferencia dos nossos antepassados animais. Tais são as palavras de Freud: "Talvez possamos começar pela explicação de que o elemento de civilização entra em cena com a primeira tentativa de regular esses relacionamentos sociais" (Freud, 1930/1996: 101). Devemos entrever, todavia, diferenças entre esses autores, pois, para Elias, essa auto-regulação implica uma evolução da vida em sociedade e, portanto, demarca uma forma de vínculo social que é historicamente datada. Já para Freud, constitui condição para a existência de laços entre os homens.

\section{O SEXUAL E A MORAL CIVILIZADA}

Em 1908, Freud (1908/1996) se interroga a respeito da causação da doença moderna. Há para ele uma relação direta entre repressão da pulsão sexual e formação de sintomas neuróticos. O debate acerca dessas novas patologias da época estava sendo travado por vários estudiosos, que, em sua maioria, imprimiam o acento nas exigências da vida moderna, como a precisão de domínio das novas tecnologias e a necessidade de aperfeiçoamento da conduta pessoal. Para esses autores, as doenças psíquicas apareciam em decorrência de um aumento de tarefas, assim como de uma maior necessidade de aperfeiçoamento e aprendizado. Freud cita-os em seu texto, não para concordar com eles, mas para enfatizar que a noção de adoecimento psíquico se relacionava, prioritariamente, com as limitações impostas à vida sexual do indivíduo moderno.

Nesse momento, é fácil observar que a sexualidade opera de forma contrária à civilização. Na medida em que é o impedimento da pulsão sexual que causa padecimento, e como esse cerceamento é conseqüente da vida em civilização, é lícito concluir que sexualidade e civilização se encontram em pólos opostos. Essa contradição caracteriza a primeira elaboração freudiana a respeito da relação entre sujeito e civilização. A sexualidade do sujeito é submetida a uma moral condizente com a época e localidade em que Freud vivia e clinicava: "[...] a influência prejudicial da civilização reduz-se principalmente à repressão nociva da vida sexual dos povos civilizados através da moral sexual civilizada que os rege” (1908/1996: 172). Assim, Freud nos fala que uma moral coercitiva da sexualidade produz padecimento psíquico: "Para a grande maioria das organizações parece ser indispensável uma certa quantidade de satisfação sexual direta, e qualquer restrição dessa quantidade [...] acarreta fenômenos que [...] devem ser considerados como uma doença” (1908/1996: 174). 
Ora, a pulsão sexual tem como característica uma possibilidade de desvio da experiência sexual genital para outros fins, como a produção artística, o relacionamento entre as pessoas, a produção científica, entre outros, e isso seria o alicerce do social. Para Freud, em 1908, no entanto, uma parcela dessa pulsão teria que ser vivida em ato, e o fechamento das expressões sexuais exclusivamente no matrimônio - relação genital que visa à reprodução - era uma exigência social demasiadamente forte para os indivíduos, que acabavam apresentando sintomas. Já aí, Freud fala dos sintomas como uma rebeldia em relação à civilização. Entre as exigências pulsionais e as normas sociais havia uma possível fuga para a neurose. O sintoma neurótico seria uma resposta do sujeito ao processo civilizatório: “[...] as neuroses, quaisquer que sejam sua extensão e sua vítima, sempre conseguem frustrar os objetivos da civilização [...]” (Freud, 1908/1996: 185). Nesse momento, todavia, o sintoma era visto como sendo causado, prioritariamente, pelo cerceamento da sexualidade, e não como uma das formas de expressão da subjetividade.

No texto intitulado "O ego e o id", Freud introduz uma instância portadora dos mais altos e nobres sentimentos, que são vistos como conquistas da civilização. Tal instância é denominada de supereu, ou ideal de eu. Ele nos diz que é papel do supereu incitar o recalque, que será realizado pelo eu: "[...] desde o início atribuímos às tendências morais e estéticas (depositadas no supereu) do eu a função de incentivar o recalque [...]" (1923/1996: 48).

Com a formulação de uma topologia marcada pela introdução do conceito de supereu, Freud entende que o sujeito padece de um conflito que lhe é interno, as exigências não advêm do mundo externo, mas de nós mesmos, ou melhor, do nosso supereu. "Os conflitos entre o eu e o ideal [...] em última análise refletirão o contraste entre o que é real e o que é psíquico, entre o mundo externo e o mundo interno" (Freud, 1923/1996: 49). Assim, parece-nos claro que é o supereu a desempenhar um papel impositor de regras morais, e é a ele que o eu obedece. É importante ressaltarmos que o supereu, a instância que desempenha uma injunção da moral, é formado por identificações parentais. O supereu parece se enquadrar na constituição da subjetividade civilizada.

A libido sexual só deixa de ser vista como a principal fonte de desprazer originado do conflito entre civilização e sexualidade - a partir da formulação de uma nova dualidade pulsional, marcada pela instauração da pulsão de morte e pela formulação de uma nova tópica, constituída por eu, isso e supereu. Para os fins do presente artigo, acreditamos ser pertinente uma explanação, em alguns pontos, das mudanças pelos quais os conceitos da teoria tiveram que passar para comportar a pulsão de morte. Abordaremos, sobretudo, o conceito de narcisismo, 
o ponto inicial da virada do pensamento freudiano que desemboca na pulsão de morte e na nova metapsicologia.

É simples perceber que a moral da qual Freud nos fala em 1908 tem um caráter coercitivo, o que nos conduz a questionar as conseqüências de sua supressão na formação psíquica do indivíduo. Se o adoecimento estava intrinsecamente relacionado às poucas possibilidades de satisfação sexual, não haveria como não pensar que maior liberdade sexual acarretaria uma diminuição do desprazer. $\mathrm{O}$ que não é dito por Freud nesse texto, porém, e que nos leva a elucubrações que, descontextualizadas, desmerecem a Psicanálise, é abordado por ele na sua última obra a respeito da relação entre sujeito e civilização - o texto de 1930 . É nesse escrito que Freud situa o sofrimento em relação à vida em civilização, implicando a constituição psíquica. O mal-estar não é ocasionado apenas por ações coercitivas referentes à sexualidade. Sujeito e civilização estão sempre lutando por maior espaço de expressão, sendo que a relação entre essas duas estruturas dificilmente chega a ser totalmente tranqüila. Como analisa Freud, "Uma satisfação irrestrita de todas as necessidades apresenta-se-nos como o método mais tentador de conduzir nossas vidas; isso, porém, significa colocar o gozo antes da cautela, acarretando logo seu próprio castigo" (1930/1996: 85).

É ainda nesse trabalho que Freud nos arrola as três fontes de sofrimento às quais o indivíduo estaria sujeito: a degeneração do corpo, os contratempos da natureza e, finalmente, as relações entre os indivíduos, sendo esta última a principal causa de sofrimento. Aqui encontramos um elo fundamental entre o texto freudiano com o que é dito por Elias em 1993. O processo civilizador, ao qual Elias se reporta, tem como principal força motriz o aumento das relações entre os indivíduos, pois quanto maior a cadeia de relacionamentos, mais complexa é a organização; e mais exigente ela o é com relação ao controle que o indivíduo tem de ter sobre si. A característica da civilização é um aumento das relações interpessoais e encontra-se diretamente relacionada ao sofrimento neurótico.

Elias acentua o modo como as relações entre os indivíduos foram dando lugar à formação da civilização conhecida nos dias atuais. "O que tem a organização da sociedade sob a forma de Estados [...] a ver com a civilização?” (Elias, 1993: 193). Segundo ele, a civilização é um processo datado historicamente e que teria como momento fundante a formação dos Estados. A elaboração desse funcionamento social faz com que aumente a interdependência entre as pessoas. Se antes as organizaçôes sociais não exigiam uma relação crescente entre os indivíduos, isso mudou a partir dos Estados. Os feudos, que eram isolados uns dos outros, a partir do aumento da competição entre eles foram se rearranjando até se 
constituírem como grupos sociais mais interligados. Isso fez com que houvesse uma mudança radical na forma como as pessoas se relacionavam. $\mathrm{O}$ aumento das relações pessoais exige um autogerenciamento, não necessário na organização social anterior.

O que, para Freud, estava em jogo na civilização, possibilitando o aumento da rede de relações entre as pessoas? "A civilização visa a unir entre si os membros da comunidade também de maneira libidinal [...]" (Freud, 1930/1996: 113). O que opera, dessa forma, para o aumento das relações é a energia sexual que Freud denominou como libido. Assim, a sexualidade estaria a serviço da civilização. Sem ela não seria possível a união entre os sujeitos. Notemos que há uma modificação, no pensamento freudiano, quanto ao lugar que o sexual ocupa relativamente à civilização. Se, em 1908, Freud aponta o sofrimento causado pela restrição à sexualidade como o principal oponente à civilização, no "Mal-estar..." é a energia sexual que liga os sujeitos entre si e que garante o laço social. Dessa forma, o aumento das relações interpessoais, considerado por Elias como caráter essencial da civilização, é possibilitado pela energia libidinal. Freud assevera, contudo, que a principal fonte de sofrimento é a relação entre as pessoas. Com efeito, a união libidinal acarreta também desprazer. Assim, a sexualidade, da mesma forma que une as pessoas, provoca, em decorrência desse fato, o mal-estar.

Agora podemos nos perguntar em que o processo civilizatório, visto como uma organização social histórica, tem a ver com a formação do sujeito neurótico. Bem, tanto Freud (1930/1996) quanto Elias (1993) nos indicam a relação direta que a civilização tem com a formação psíquica individual. Se não fosse dessa forma, não teríamos como discorrer acerca das mudanças ocasionadas tanto na sociedade quanto no indivíduo. Assim, temos que pensar essas duas estruturas interligadas: "[...] não podemos deixar de ficar impressionados pela semelhança existente entre os processos civilizatórios e o desenvolvimento libidinal do indivíduo" (Freud, 1930/1996: 103). Dessa forma, há certa analogia entre o desenvolvimento da civilização e do indivíduo. Ao utilizarmos o pensamento de Elias, atribuímos à divisão subjetiva uma dimensão histórica que a constitui. Pensamos que o sujeito com o qual tratamos é o resultado de uma série de acontecimentos históricos, dos quais ressaltamos o processo civilizador.

Já acentuamos que entre o texto de 1908 e o de 1930 há diferenças, no pensamento de Freud, no que diz respeito ao entendimento da relação que o sujeito mantém com a civilização. Em 1908, os objetivos da civilização e da subjetividade pareciam divergir no que diz respeito à expressão da sexualidade. De 
acordo com Freud, a moral vigente exigia uma supressão da sexualidade, e o adoecimento subjetivo estava relacionado a tal imposição. Já no "Mal-estar...", os objetivos dessas duas unidades continuam a divergir, mas as leis impostas pela vida em civilização dão origem à subjetividade. Queremos ressaltar que o texto de 1930 rompe com a idéia da dicotomia entre civilização e sujeito, como se estas fossem duas unidades independentes que tivessem de conviver. Seriam, na realidade, duas unidades que se constituiriam simultaneamente, não havendo subjetividade sem civilização, visto que o sujeito se constitui no momento em que se instaura a regulação entre os indivíduos. Nessa ocasião, já se havia transposto a cena do conflito, que passou a ser interiorizado e representado pela dualidade pulsional - pulsão de vida versus pulsão de morte.

Podemos nos indagar qual a necessidade de um gerenciamento individual que assegure uma aproximação do funcionamento subjetivo às leis morais. O que essas leis proíbem? Por que são necessárias para uma vida comunal? Freud, ao discorrer acerca das interdições, revela que há uma inclinação individual para a agressividade que teria que ser controlada a partir da instauração de uma moral: "A existência da inclinação para a agressividade [...] constitui o fator que perturba nossos relacionamentos com o nosso próximo e força a civilização a um tão elevado dispêndio de energia" (1930/1996: 117).

Não podemos, no entanto, dar continuidade a esse pensamento sem antes fazermos referência ao texto de que Freud se utiliza para dar conta do começo da civilização. Estamos falando de "Totem e tabu" (1913/1996). Nesse trabalho, Freud ressalta que na origem da civilização está o assassinato do pai pelos filhos, e é nesse crime que repousa a nossa moral civilizada. $O$ pai assassinado não era apenas repudiado pelos seus filhos, que não podiam obter os privilégios que este possuía, tal como a liberdade sexual, mas era também amado por eles. A identificação com o pai remonta à constituição do supereu arcaico, caracterizado pelo seu caráter tirânico.

Dessa forma, o crime cometido fez com que, primeiro, houvesse a união dos irmãos num grupo e, segundo, que estes se sentissem arrependidos do seu ato, passando a repudiá-lo. $\mathrm{O}$ mito freudiano a respeito do começo do enlaçamento social, ocorrido a partir da união dos irmãos da horda contra o pai tirânico, permite contextualizar o desejo de assassinato, ou melhor, o desejo de destruição.

Ora, na era primeva, conforme Freud (1913/1996), só se estabeleciam relações de força e a vida sexual não era regrada. Assim, segundo Enriquez (1990), a partir da invenção da primeira relação de solidariedade e do reconhecimento do outro, ao mesmo tempo como diferente e semelhante, são estabelecidos vínculos fraternos. 
A preocupação que os irmãos passaram a ter foi que nenhum deles ocupasse o lugar do pai. Mesmo hipoteticamente, o ato (de ocupar o lugar do pai) poderia se concretizar. Dessa forma, é assim que esses irmãos passam a ver uns aos outros como potenciais inimigos, e um desejo de destruição do outro surge.

Agora, podemos abordar as formulaçôes de Freud (1930/1996) sobre a agressividade relativa à pulsão de morte, que remonta ao assassinato constitutivo da civilização. Dessa forma, o enlaçamento social é, desde sua origem, portador de sentimentos de destruição e agressividade com relação ao próximo. É essa agressividade, esse desejo de destruição do próximo que tem de ser cerceado. A lei incide onde o desejo ameaça o social.

No primeiro texto freudiano, o de 1908, não há menção aparente à restrição de uma agressividade dirigida para os outros. Esta vem à tona em 1930 porque Freud faz uso das suas formulações do "Totem e tabu". A agressividade seria o principal obstáculo oferecido à civilização pelo indivíduo.

Elias (1993), ao aludir à constituição do processo civilizador, considera um outro ponto, tão importante quanto o aumento da interdependência, que seria a monopolização da força física. Com isso, a agressividade e a violência não seriam mais expressas livremente por todos os indivíduos, mas confinadas a um lugar, o exército, por exemplo, e a uma ordem. Assim, os indivíduos não estariam mais sujeitos às volúpias dos outros. $\mathrm{O}$ monopólio assegura que as ameaças que os indivíduos sofrem uns dos outros sejam controladas e menos relacionadas com a força física. Como afirma Freud (1930/1996), ao nos tornarmos civilizados trocamos uma quota de satisfações pulsionais por maior segurança em grupo.

É a agressividade, principal representante da pulsão de morte, que vai ocupar o lugar da libido no que se refere ao conflito entre o social e o individual. "O nome libido pode mais uma vez ser utilizado para denotar as manifestaçôes do poder de Eros, a fim de distingui-las da energia do instinto de morte" (Freud, 1930/1996: 125). Assim, podemos pensar que a sexualidade, mais propriamente sua energia, está a serviço da união entre os indivíduos, e o que se opõe são os componentes da pulsão de morte.

É para conter a agressividade que surgem no funcionamento psíquico do sujeito formaçôes reativas, tais como o supereu. Essa instância, aperfeiçoada a partir das exigências da civilização, é responsável pela internalização das proibições e pela formação de uma consciência mais severa do que qualquer instituição externa, visto que dela não podemos fugir. É em relação ao supereu autoritário que a neurose se formula. As expressões pulsionais agressivas, antes em cena no próprio mundo, são transportadas para dentro do sujeito, que passa a sofrer de um conflito interno que o torna civilizado. 


\section{Auto-regulaÇÃo ocasionada Pelo SENTIMENTO DE CUlPa E SUA RELAÇÃO COM O NARCISISMO}

Podemos notar que os pensamentos de Freud e Elias (1993 e 1994) coincidem no que diz respeito ao controle de si exigido pela vida em comunidade. "A substituição do poder do indivíduo pelo poder de uma comunidade constitui o passo decisivo da civilização" (Freud, 1930/1996: 102). Isso quer dizer que a livre expressão dos sentimentos e paixões individuais tem que ser controlada para que não comprometa o enlaçamento social. Freud refere-se ao conceito de justiça quando se reporta à vida em sociedade. As leis carregam em si o preceito de que não serão desobedecidas em favor de um só indivíduo, pois que servem à massa e, como tal, exigem restrições pulsionais de cada um.

O conceito de justiça e a formação de um monopólio da força física, segundo Elias (1993), se dirigem para o mesmo ponto, a saber, o autocontrole individual. Este se caracteriza por gerenciamento interno, cálculo, reflexão, conhecimento de si, capacidade de previsão, reconhecimento dos signos expressos nas ações dos outros.

É interessante destacarmos essa noção de cálculo com a qual lidamos, quando nos referimos à constituição psíquica. O sujeito neurótico é aquele que tem que ficar fazendo as contas das suas possibilidades de gozo, controle e expressão pulsional interligados na constituição subjetiva. Essa luta interna, todavia, não é algo inerente apenas ao sujeito; pelo contrário, tivemos que ter uma nova organização psíquica para lidarmos com a exigência da auto-regulação oriunda da civilização. As leis, os códigos de conduta, que se apresentavam, a princípio, como sendo reivindicações externas com as quais tínhamos que lidar, "[...] no medo do indivíduo de degradar-se ou simplesmente perder o prestígio na sociedade em que vive” (Elias, 1993: 213), tiveram que ser internalizados e convertidos em angústia individual.

O que faria, porém, com que nos policiássemos o tempo todo? A perda de prestígio, ou, como nos transmite Freud (1930/1996), de amor, é uma das respostas, mas não a mais completa. Se assim o fosse, bastaria que nos regulássemos apenas na presença de um outro que apreciamos e do qual não quiséssemos perder a admiração. O que se passa, no entanto, é que o autocontrole não se restringe a algumas esferas. Dessa forma, teríamos que lançar mão de um conceito trabalhado por Freud em "O mal-estar na civilização", o qual nos ajuda a entender o porquê de uma auto-regulação crescente.

O sentimento de culpa é apontado por Freud (1930/1996) como o produto das relações que os indivíduos mantêm uns com os outros. Expresso de outra forma, no enlaçamento social os indivíduos têm que introjetar uma parcela de 
agressividade em nome de uma vida em civilização. Como esta introjeção da agressividade dá origem ao supereu, o conflito interno que se origina entre o eu e o supereu pode ser denominado de sentimento de culpa. Tal sensação é responsável pela equivalência entre ação e desejo. Dessa forma, tanto a ação, realizada efetivamente, como o desejo passam a ser punidos igualmente. Assim, o sentimento de culpa se distingue do remorso, pois ele não vem necessariamente após uma ação tomada como má. $\mathrm{Na}$ realidade, tal sentimento se antecipa à ação, evitando-a.

A partir do aumento da interdependência entre as pessoas, o sentimento de culpa passa a funcionar como uma lei interna, uma auto-regulação que cerceia nossas possibilidades de gozo. A conseqüência de uma não-regularização do gozo é o aumento desse sentimento. "[...] o preço que pagamos por nosso avanço em termos de civilização é uma perda de felicidade pela intensificação do sentimento de culpa" (Freud, 1930/1996: 137).

Nesse momento, faremos uma digressão na teoria freudiana sobre o eu para nos auxiliar no entendimento desse autogerenciamento que nos torna sociáveis. $\mathrm{Na}$ obra de Freud, podemos observar um deslocamento referente ao funcionamento do eu. Falamos aqui dessa instância visto ser ela a responsável pela relação que o sujeito estabelece com o que lhe é exterior e por ela comandar o recalque. $\mathrm{O}$ conceito de narcisismo é importante porque sua introdução, na teoria freudiana, marcou as mudanças referentes ao eu e ao dualismo pulsional.

No primeiro dualismo pulsional, a saber, pulsões de autoconservação e pulsões sexuais, a libido refere-se apenas a esta última, sendo o eu o responsável pelas pulsões de autoconservação. Quando, em 1914, Freud (1914/1996) elabora o conceito de narcisismo - estádio intermediário entre o auto-erotismo e a escolha objetal -, o eu passa a ser compreendido como objeto da libido. Isso faz com que surja um impasse na teoria freudiana. Se a libido não serve apenas às pulsões sexuais, que se oporiam às do eu, mas também investe o eu, como se sustenta um conflito no qual a força impulsionadora dos dois pólos é a mesma? Freud lança mão de outro par de opostos para tentar resolver esse problema. Fala-nos então das pulsões do eu em contrapartida às objetais. Essa mudança não chega a solucionar totalmente o problema, mas auxilia Freud a manter a existência de um conflito, sem o qual não haveria como pensar o sintoma. É apenas com a introdução da pulsão de morte que o dualismo se ergue novamente.

Na compreensão de Montenegro (2002), as mudanças ocasionadas pela introdução do narcisismo na formulação do eu impõem a seguinte questão: "Em que medida essa organização mental, que passa a deter o controle sobre a distri- 
buição da libido, adquire atributos semelhantes àqueles conferidos a uma certa noção de sujeito, tributária da filosofia da consciência, em que o eu implicaria uma unidade deliberativa, detentora do controle da intencionalidade?" (Montenegro, 2002: 226).

Consoante a autora, a resposta poderia ser buscada na formulação do conceito de supereu. Seguiremos, então, esse caminho apontado por Montenegro, para dar continuidade a nosso argumento.

No texto de 1923, Freud faz referência à construção de um novo modelo de funcionamento mental, que iria complementar e retificar a primeira tópica. Nele, as instâncias deixam de ser vistas como estruturas diferentes que se comunicam e são concebidas de maneira mais interdependente. Dessa forma, o inconsciente não é uma instância isolada, que luta por se expressar na consciência, mas passa a fazer parte, como qualidade, de todas as instâncias, a saber, o eu, o isso e o supereu. Com isso ficou frisado que uma parte do eu era também inconsciente; mais propriamente, que as resistências do eu, responsáveis pelo recalque são inconscientes.

É também nessa obra que Freud (1923/1996) explica a formação do eu, sendo que esta ocorre, prioritariamente, a partir das identificações. Assim, ressalta Montenegro: "A identificação consiste em um mecanismo bastante arcaico, através do qual o eu constrói seus alicerces” (Montenegro, 2002: 225-226). Em parte essas identificações são responsáveis também pela criação de um ideal de eu, que "passa a funcionar como uma espécie de agente observador, de modo a regular suas ações e conferir-lhe a medida da auto-estima” (Montenegro, 2002: 226). Esse ideal é nomeado por Freud de supereu.

Dessa forma, podemos observar que as instâncias responsáveis pelo funcionamento social, o eu e o supereu, surgem um a partir do outro. Assim, a pergunta que fizemos, a respeito da necessidade de autogerenciamento, ganha aqui outra nuança. Regulamo-nos porque funcionamos em relação ao outro e para o outro. Tal referência ao outro, segundo Montenegro (2002), é estabelecida por meio do narcisismo, evidenciando a importância do outro na constituição do aparelho mental.

Por conseguinte, à guisa de conclusão, a auto-regulação, que, segundo Elias (1994), caracteriza o funcionamento de um indivíduo em civilização, é produto das instâncias auto-reguladoras, que por sua vez se originam a partir das exigências de uma vida social. Assim, podemos observar o quanto essas estruturas são interdependentes, mostrando a inter-relação dos indivíduos entre si e a submissão à ordem social. 


\section{REFERÊNCIAS BIBLIOGRÁFICAS}

Elias, N. (1993). O processo civilizador: formação do Estado e civilização, vol. 2. Rio de Janeiro: Jorge Zahar.

. (1994). O processo civilizador: uma história dos costumes, vol. 1. Rio de Janeiro: Jorge Zahar.

Enriquez, E. (1990). Da Horda ao Estado: psicanálise do vinculo social. Rio de janeiro: Jorge Zahar.

Freud, S. (1908). Moral sexual "civilizada" e doença nervosa moderna. Edição standard brasileira das obras psicológicas completas de Sigmund Freud, vol. 9. Rio de Janeiro: Imago, 1996.

. (1913). Totem e tabu. Edição standard brasileira das obras psicológicas completas de Sigmund Freud, vol. 13. Rio de Janeiro: Imago, 1996.

. (1914). Sobre o narcisismo: uma introdução. Edição standard brasileira das obras psicológicas completas de Sigmund Freud, vol. 13. Rio de Janeiro: Imago, 1996.

. (1923). O ego e o id. Edição standard brasileira das obras psicológicas completas de Sigmund Freud, vol. 19. Rio de Janeiro: Imago, 1996.

(1930). O mal-estar na civilização. Edição standard brasileira das obras psicológicas completas de Sigmund Freud, vol. 21. Rio de Janeiro: Imago, 1996.

Montenegro, A. (2002). Pulsão de morte e racionalidade no pensamento freudiano. Fortaleza: Editora UFC.

Recebido em 1 de agosto de 2006 Aceito para publicação em 23 de novembro de 2006 